\title{
RICARDO CARVALHO CALERO, PROFESOR E LINGÜISTA
}

\author{
RICARDO CARVALHO CALERO, TEACHER AND LINGUIST
}

Francisco Fernández Rei

\section{LEMBRANZA DE DON RICARDO}

Estudei a licenciatura de Filosofía e Letras (Románicas: Español) no mesmo andar deste edificio da Universidade de Santiago de Compostela (USC) en que hoxe a Academia honra a don Ricardo, como lle chamabamos os alumnos e alumnas; e en aulas deste mesmo andar, entre 1971 e 1974, asistín ás clases das súas de lingua galega de $3^{\circ}$ curso, literatura galaico-portuguesa medieval de $4^{\circ}=$ e literatura galega moderna de $5^{\circ}$.

Con 18 anos, por primeira vez na miña vida, ía poder ter clases da lingua, e na lingua, que falaba desde meniño. Antes de matricularme, xa coñecía a súa gramática (a 3a edición, 1970), sabía do seu método pedagóxico e tamén que controlaba a asistencia ás aulas. Preparaba con rigor cada clase para que as materias optativas que impartía tivesen a maior dignidade posible, e abofé que o conseguiu루.

Das aulas de literatura moderna conservo unha lembranza inmellorable. Esgotárase a 1ํe edición da súa Historia da literatura galega contemporánea, que abranguía o século XIX, e non aparecera a 2ạ edición, ampliada a 1936; pero tiñamos para nós o protagonista do maior esforzo de sistematización da literatura galega. Lembro o excelente tratamento da biografía e da obra de Rosalía e a paixón ó explicar figuras da nación do século XX que tratara moito e que tanto venerara e admirara, como Cabanillas, Pedrayo ou Castelao.

Xa non era o profesor tan distante dos cursos anteriores. Tiñamos obras de lectura obrigatoria e un traballo individual do que facía un seguimento. A min

1 Sobre os seus obxectivos, unha vez instalado na cátedra, comentáballe a Carmen Blanco (1989, p. 46-47): "Quixen, desde logo, que non se mirase o galego como unha asignatura máis ou menos encamiñada a facer exercicios espirituais de galeguidade. Estes exercicios espirituais son mui recomendábeis, pero o lugar de realizalos non é, de nengunha maneira, a cátedra. Esforceime porque os estudos atinxisen o nivel académico desexábel e, aínda que as actas demostran que o número de aprobados era mui elevado, non obstante procurei que, de todas formas, houbese unha certa peneira que non permitise que a asignatura fose depreciada polo exceso de facilidade con que se aprobase". 
mandárame estudar a vida nas aldeas de Berres, Laza e Vilardevós en textos de Manuel García Barros, Alonso Obregón e Silvio Santiago. Conservo a penúltima versión do traballo, con anotacións súas e asinado; a versión final mandoulla a Fernández del Riego, que a publicou no Grial 71.

Nos luminosos corredores deste primeiro andar da antiga Facultade de Filosofía e Letras, cruceime e saudei un bo quiñón de veces aquel home tan serio, de andar solemne. Un día achegouse a min e deume os parabéns por obter a cualificación máxima na materia de literatura galega moderna, xesto que moito me sorprendeu e me alegrou. Semanas despois formou parte do tribunal da miña memoria de licenciatura sobre a cultura mariñeira de Cariño; e cando defendín a tese de doutoramento sobre a morfoloxía verbal do galego oral, tiven a honra de que a xulgase nun tribunal presidido por Alonso Zamora Vicente.

Como dixen, admiraba moito a Ramón Cabanillas, que quería que o considerase "sempre como un discípulo, como un fillo" ${ }^{2}$. Cando a Academia no 1976 lle dedicou o Día das Letras ó poeta cambadés, encargoulle a don Ricardo unha escolma poética do homenaxeado ${ }^{3}$. Ese ano, na cátedra publicou as sagas de $\mathrm{Na}$ noite estrelecida e planificou un libro de homenaxe da USC para que profesorado e persoas investigadoras da acabada de crear Facultade de Filoloxía tratasen a obra do autor de Vento mareiro; e como sabía que eu era da vila natal de Cabanillas, pediume, a través de Constantino García, unha colaboración.

Foi unha inmensa honra participar nesa homenaxe, que se abre coa edición das cartas que o poeta lle mandara a don Ricardo desde Madrid, Lugo, Cambados... e que se fecha cun longo traballo meu sobre a lingua e a situación social do galego da viliña de Fefiñáns, "hoxe axugada á vila de Cambados". Anos despois, cando José Luis Rodríguez me invitou a participar na homenaxe da Universidade compostelá e do Parlamento de Galicia a don Ricardo, colaborei cun texto sobre

2 "O que non me parez tan ben é que por escrito me trate de vostede. Cando me ten diante non se atreve a facelo. Non o faga tampouco por carta, que non llo merezo, pois ben sabe cánto o quero e cómo desexo que considere sempre como un discípulo, como un fillo" (Carballo 2006, p. 569; carta a R. Cabanillas de 28 de novembro do 1958).

3 "Cabanillas queríame muito, e eu quíxeno muito tamén. Tiña intención de que eu lle fixese unha antoloxía de poemas. Cabanillas é un escritor mui fecundo, publicou muitísimos versos, case todos están collidos na súa obra completa, na que eu fixen unha introdución. Mais na época en que eu o coñecín, Cabanillas agradábame sobre todo porque carecía de vaidade, paréceme que era un home xa chegado a unha serenidade que lle permitía desdeñar as formas externas da gloria literaria; e el decíame que entendía que producira demasiados versos e que lle interesaría que se fixese unha antoloxía co máis selecto da súa obra e desexaba que eu realizase ese labor, pero nunca mo encargou dunha maneira perentoria. Sen embargo, eu fixen algo parecido a isto cando a Academia Galega designou a Cabanillas figura epónima para o Día das Letras e me encargou a publicación do tomiño que cada ano adica á figura escollida, e entón intentei facer o que Cabanillas desexaba, seleccionando poesías de diversos temas con arreglo a certas orientacións que nunha carta me dera sobre o particular" (Blanco 1989, pp. 154-155). 
os dialectalismos, os arcaísmos e os empréstitos do portugués na construción da lingua literaria de Cabanillas,

No primeiro semestre do 77 coincidimos nalgún dos seminarios das Bases prá unificación das normas lingüísticas do galego (USC 1977), o maior esforzo e o máis plural intento normativo da década de 1970. Nunha crítica positiva que fixo desas Bases que promovera o Instituto da Lingua Galega (ILG), definiunas como "documento conciliador". Despois, saudámonos na rúa ou na libraría Couceiro, nunha xeira en que defendiamos posicións contrapostas sobre que é o galego hoxe verbo do portugués.

Nos anos 80 só lembro falar con el en dúas situacións, e ben distintas. A primeira foi o 23 febreiro do 1981, cando o coronel Tejero acababa de asaltar o Congreso dos Deputados ${ }^{4}$. Esa tarde, despois das seis, saíra do meu despacho, que estaba no mesmo andar do seu na antiga Facultade de Filoloxía da praza de Mazarelos, e don Ricardo saíu ó corredor, só estabamos os dous e púxose a contarme o que estaba a pasar no Congreso. Eu nada sabía do tejerazo. Despedímonos, porque el quería marchar para a casa para ter información directa polo televisor. Eu fixen o mesmo.

A finais dos 80, cando andaba a loitar cun cancro, sabía do seu estado por Carme García Rodríguez, que fora colaboradora súa na cátedra. En xaneiro do 90 Carme contoume que estaba moi mal de saúde e moi doído coa actitude dos seus irmáns galeguistas, polo que me propuxo írmolo visitar. Como non tiña ningunha relación persoal con el nin coa familia, a desculpa que se me ocorreu foi ir invitalo para participar na homenaxe a Constantino García, que eu estaba a coorganizar como director do Departamento de Filoloxía Galega. Sempre resultaran cordiais as relacións entre o primeiro director do ILG e don Ricardo, que fora tamén o primeiro secretario do padroado do Instituto e o seu subdirector de 1972 a 1978; ademais, contestara o discurso de ingreso de don Constantino nesta Academia. A enfermidade avantara moito, pero a súa lucidez e a súa memoria parecíanme intactas. Moi amablemente díxome que tiña que facer unhas probas médicas e que, cando se recuperase, poríase a redactar algo para esa homenaxe.

Foramos visitalo o mesmo día en que Fraga Iribarne chorara emocionado ó ser investido presidente de Galicia. Con finezza falounos das bágoas de Fraga e como vía a autonomía neses momentos, e a seguir lembrounos os esforzos e os soños da

4 Verbo disto contáballes a Fernán-Vello e a Pillado (1986, p. 230): "Achava-me no meu despacho da Universidade cando un compañeiro me participou que ao través dun aparato de rádio se ouvian detonazóns producidas por armas de fogo na sesón do Congreso que se estava a celebrar. Imediatamente comprendin que se tratava dun golpe de mao realizado por forzas insurxentes. Trasladei-me à miña casa para obter informazón directa ao través do meu televisor e permanecin frente a el até a mañá do dia seguinte, depois que vin sair à Carreira de San Xerónimo os deputados cuxo secuestro rematara". 
súa xeración para conseguir a autonomía e tamén o difícil que fora a súa vida e a dos galeguistas que no franquismo seguiran loitando pola causa de Galicia. Foi a primeira e única vez que lle ouvín falar de temas alleos a cuestións académicas e lingüísticas.

Na tarde do 25 de marzo do 1990 deixei o ILG para asistir ó seu funeral na igrexa compostelá de San Francisco. Como aínda non chegara o cadaleito, agardei acaroado ó monumento de Asorey ó santo de Asís; e rematado o funeral, desandei o camiño e volvín para o ILG. Semanas despois, cando retiraron os seus efectos persoais do despacho da Facultade de Filoloxía de Mazarelos, do que gozou na xubilación, tomei posesión dese espazo para a dirección e o arquivo do Departamento de Filoloxía Galega.

\section{CARVALHO, LINGÜISTA CON VOCACIÓN MILITANTE E SERODIA}

Na monumental Historia da literatura galega contemporánea investiu anos para xuntar datos, consultar textos e sistematizar a materia. A súa vocación primeira foi a literaria, para logo concienciarse do valor do instrumento lingüístico na creación. Definíase como "filólogo en xeral", que nunha época da vida non se ocupara de "aspectos da lingua considerados en si mesmos, senón que estudaba a lingua como instrumento de expresión artística”. Fíxoo máis tarde ó redactar a gramática, cando se viu obrigado a considerar a lingua en conxunto, para logo ocuparse de traballos estritamente lingüísticos, aínda que moitos deles se relacionaban con estudos literarios (Blanco 1989, pp. 96-97).

A finais do 1963, cando non era lingüista nin gramático, asumiu resignado, e con vontade de servizo a Galicia, a redacción dunha gramática para a editorial Galaxia. Na correspondencia con Fernández del Riego manifesta o seu desacougo con esa encarga, sabedor de que persoas que poderían redactala non quixeron "arriscar o seu prestixio nista tarefa, que considerarán política e non científica".

En 1966 publicou a Gramática elemental del gallego común (en adiante, a Gramática). O seu modelo de lingua non é o que fala o pobo, senón o literario, o das

5 "En fin, eu estóu xa embarcado na empresa, que me resulta penosa, e que posiblemente non satisfaga a ninguén: pero se a considerades necesaria iquén a ía facer? Os capacitados pra elo difícilmente quererían arriscar o seu prestixio nista tarefa, que considerarán política e non científica. Terán medo a Dámaso Alonso, que ten dito que por moito tempo non será posible unha Gramática galega como a catalana de Badía. Isto é certo, pero nós queremos facer outra cousa. Mais hai moitos que consideran que isa outra cousa non hai por qué a facer. É decir, que creen que o mellor é non facer nada" (Carballo 2006, pp. 395-396). Para o proceso de xestación e de elaboración da Gramática e as dificultades a que se enfrontou véxanse Freixeiro (2011, pp. 73-77), Montero (2011, pp. 133-136; 2020b, pp. 286-290) e González González (2020, pp. 119-124). 
persoas cultivadas ${ }^{6}$. Na introdución da $1^{\underline{a}}$ edición manifesta que tratará de describir o galego actual, unha lingua viva; porén

esta lengua viva no es el gallego vulgar, profundamente alterado en su pureza por la erosión de la lengua oficial y reducido en muchos casos a diferentes formas coloquiales empobrecidas. Es el gallego culto, el gallego literario, que aspira a ser un instrumento cabal de cultura, el que nos interesa (Carballo 1966, p. 13) ${ }^{7}$.

En todas as edicións, por exemplo, considera bo galego antre ${ }^{8}$, forma moi popular que emprega Rosalía, mentres que etiqueta de vulgarismo corenta, que xa usaban Sarmiento e Pintos e que é a forma da gramática de Saco e Arce, con presenza constante na de Carvalho; e desde a 4⿳ạ edición considera vulgar meirande, con uso literario desde finais do século XIX.

A Gramática está redactada en castelán, feito que xustificou con argumentos de conveniencia didáctica e polas limitacións que impoñía o franquismo (Blanco 1989, p. 100). A lingua estatal é referencia constante nunha obra en que só se describen e ilustran as diferenzas do galego con ese idioma. Isto explica que na $4^{\underline{a}}$ edición (Carballo 1974, p. 189) afirme que en galego "pueden darse contracciones del reflexivo o recíproco se con las formas del pronombre de tercera persona que representan el objeto directo" (so, sa, sos, sas $)^{9}$; ou que en todas as edicións, en apartados da sintaxe, aparezan exemplos con pronomes átonos que son castelanismos sintácticos ${ }^{10}$.

6 En palabras de Rosario Álvarez (2011, p. 24), "O seu arquetipo é a linguaxe das persoas refinadas, isto é, urbanas e cultivadas, non o pobo galegofalante. Traslada así o prexuízo de que son as elites as que deben marcar o camiño da lingua correcta - como ocorreu adoito noutras sociedades-, sen lles dar a voz aos falantes como se comeza a propugnar na lingüística da época; pero sobre todo, desconsiderando que na situación sociolingüística de Galicia debería resultar evidente que non poden servir de fonte os que non o teñen como lingua habitual".

7 Anos despois, na $4^{a}$ edición sinala que "el habla rústica espontánea ya no crea gallego, pero aún no se ha extinguido su fuerza modeladora para la adaptación del castellano" (Carballo 1974, p. 65).

8 "Esta forma [antre] es la empleada por Rosalía. Muchos emplean entre" (Carballo 1966, p. 180, n. 187).

9 Na 7 a edición (Carballo 1979a, p. 196) mantén ese texto e engade este parágrafo: "Pero aunque todos estos ejemplos están tomados de la literatura o del uso oral de ciertas comarcas, el gallego común evita en general, como el portugués, estas construcciones, por no sentir verdaderamente al pronombre se como capaz de admitir para objeto las formas pronominales $o, a$, os, as, a causa de su valor de signo de pasiva". Poida que se documente esa contracción no galego literario ou, como di Mariño (2002, p. 77), poida que exista "nun galego urbano fortemente interferido polo castelán"; con todo, despois de varias décadas rexistrando e estudando o galego oral, estas estruturas non se documentaron no dominio lingüístico galego.

10 Sobre o castelán como referencia, Mariño (2002, p. 77) sinalaba que "en calquera caso, intencionalmente buscada ou simplemente forzada, a presencia constante do castelán como punto de referencia non soamente produciu o efecto inmediato de que o autor renunciase de entrada a facer unha gramática 
A obra converteuse nun fito na historiografía lingüística galega. Nos anos 60 e 70 foi o principal instrumento para aprender a gramática da lingua propia de Galicia, con innegable influencia normalizadora ${ }^{11}$.

\section{GALEGO AUTÓNOMO E GALEGO REINTEGRADO}

Nas primeiras edicións consideraba que o galego era "lengua autónoma, desprendida del tronco gallego-portugués" (Carballo 1966, p. 32; 1968, p. 38; 1970, p. 38) e na revisión da 4 a edición aínda o consideraba lingua de seu (Carballo 1974, pp. 71-72).

No artigo "Sobre os dialectos do galego" $(1969$, p. 4) sinalaba que "o galego (-portugués) aparez hoxe dividido en dous complexos dialectás: o galego (moderno) e o portugués. $O$ galego representa en moitos aspeitos o tronco primitivo. Ten conservado formas arcaicas que o portugués perdéu". Analizaba as diferenzas morfolóxicas actuais deses dous complexos para logo sinalar que "máis importantes son as diferencias fonéticas, que supoñen un obstáculo infranqueabre para os que soñan unha unificación total da ortografía dos dous idiomas".

Segundo Montero Santalha (2020a, p. 120), a primeira manifestación pública reintegracionista faina a mediados dos 70 nun artigo xornalístico (Carballo 1975). Xa non considera o galego lingua autónoma, polo que no limiar da $7^{\mathbf{a}}$ edición (1979a) fala da "necesidad de una reintegración del gallego en su mundo originario".

O portugués vaise converter en referente fundamental, o que explica que, por exemplo, na morfoloxía verbal prefira agora as formas de, des... esté, estés... e que considere vulgarismos dea, deas... estea, esteas... (Carballo 1979a, p. 230, n. 105; p. 233, n. 116); e se nas seis primeiras edicións da Gramática se manifestaba explicitamente en contra da ortografía etimolóxica co emprego de $\langle\mathrm{g}\rangle,\langle\mathrm{j}\rangle$ $\mathrm{e}<\mathrm{x}>$ para representar o fonema prepalatal fricativo xordo $/ \mathrm{S} /$, por considerala

descritiva do galego que fose completa e non parcial ou complementaria da castelá, senón que nalgún caso acabou por condiciona-la propia descrición gramatical do galego".

11 Para Serafín Alonso (2000, p. 462), "estamos ante un volume que aparece no panorama da década dos sesenta e setenta como un logro cultural de máis elevado valor simbólico ca estrictamente científico. Un producto editorial que cumpriu o seu papel ata a chegada da gran revolución que experimentarán o estudio e o coñecemento científicos da lingua no último cuarto do século XX. Con todo, o intento de recompilación e exposición do código maioritario da Galicia da época - o denominado galego literario-, conserva a súa vixencia non como testemuña, senón como xuíz e parte das iniciativas emprendidas para a reconstrucción, a unificación e o fomento do galego escrito na posguerra". 
"incongruente" e "arbitraria" 12 , agora propugna unha escrita etimolóxica co uso deses tres grafemas ${ }^{13}$.

Fronte a quen defendía a individualización do galego moderno como lingua non subordinada ó portugués nin ó castelán, a proposta de Carvalho do galego reintegrado supuña a súa satelización na órbita do portugués, como antes podía converterse en satélite do castelán pola indefensión sociohistórica; porén, a súa proposta non era unha adopción do portugués como lingua de cultura dos galegos. A súa satelización "consiste nunha adecuación parcial da ortografía e da morfoloxía de maneira que se permita manter unha pronunciación galega sen demasiada arbitrariedade gráfica" (Santamarina 1989, p. 293) ${ }^{14}$.

Por que se deu esa mudanza na súa consideración do galego nas sucesivas edicións da Gramática, aínda que el dicía que era unha "evoluzón"? ${ }^{15}$ A comezos dos 70 Lapa consideraba que nin a fala nin a literatura galegas serviran para crear o galego literario e que a única saída estaba en aceptar o portugués literario ${ }^{16}$. Segundo Montero Santalha (2020a, p. 118), o artigo de Lapa foi unha "sacudida" na consciencia de Carvalho, que vai prestar máis atención ás perspectivas de futuro da lingua ó comprender "que não era razoável continuar indefinidamente

12 "El fonema $\int$ se representa por $x$. El intento de ortografía etimológica, que utilizaría $g, j$ o $x$, es incongruente, pues sería arbitraria la elección de cualquiera de estos símbolos en el caso frecuente de que no hubiera ninguna de esas letras en el étimo: PERSĬCU > pexego, PASSĂRU > paxaro, CAPSŬLA > caixa. Además, si FUGĚRE puede reflejarse en fugir, FUĞ̌ no puede estar representado en la escritura por fugo, pues go no se lee $\int o$. El modelo del gallego medieval o del portugués no sirve, pues en la lengua arcaica y en la actual del vecino país, $g^{e}, g^{i}, j$ representan una palatal sonora 3 , que el gallego moderno no conserva y que no siempre corresponde a $g$ o $j$ en latín. Es decir, que hay razones fonéticas para que se empleen siquiera dos grafías; pero en nuestro caso tenemos un solo fonema, y no parece lógico ni práctico exigir erudición histórica al que escribe" (Carballo 1966, p. 78). E o mesmo texto en Carballo (1968, p. 90; 1970, p.

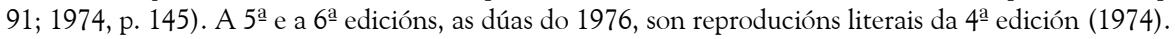

13 "El fonema $\int$ se representa por $x$. Una ortografía etimológica más culta conserva el uso de g o j para representar el fonema sonoro 3 del gallego antiguo, hoy ensordecido" (Carballo 1979a, p. 150).

14 Na súa xeira reintegracionista, manifestaba que non se debía "adoptar sen máis a ortografía portuguesa" e que se debería "estudar cada caso e ver o que é aceptábel e o que non en cada momento" (Blanco 1989, p. 190), Verbo do léxico dicía que "non hai necesidade de utilizar termos usuais no portugués normativo, cando existen termos consolidados dentro da nosa área galega" (Fernán-Vello e Pillado 1986, p. 179).

15 Carvalho manifestou que houbo "unha evoluzón que segue unha liña absolutamente recta" e que de ningún xeito "se pode crer que a última edizón, a anterior á miña xubilazón no posto de profesor de galego, supoña unha rectificazón da primeira edizón publicada en 1966”. A 7̊ edición da Gramática está implícita na 1a edición e, entre esta e a derradeira, "máis que evoluzón de doutrina, hai aplicazón sucesiva que se vai acomodando, na súa exposizón en cada caso, ás posibilidades reais de actuazón práctica de cada momento" (Fernán-Vello e Pillado 1986, pp. 175-177). Na análise que fai Monteagudo (2020) da súa evolución sobre a lingüicidade do galego, demostra que arredor do 1975 si houbo mudanza.

16 "Nada mais resta senão admitir que, sendo o português literário actual a forma que teria o galego se o não tivessem desviado do caminho próprio, este aceite uma língua que lhe é brindada em salva de prata" (Lapa 1973, p. 286). 
na inércia histórica do stand-by quando as circunstâncias sócio-políticas introduziam uma situação nova -e dramática”.

O influxo de Lapa na súa nova postura sobre o galego parece innegable; con todo, como suxeriu Freixanes (2020, p. 111), tamén puido influír sentir que os seus irmáns galeguistas non contaban con el ou que deixaran de lle amosar a consideración que lle tiñan, ó apareceren "novos traballos filolóxicos, novas demandas e novas xeracións de estudosos da lingua, novas metodoloxías de campo, novas propostas (o Instituto da Lingua Galega créase no ano 1971)”.

Do 1979 é a súa disxuntiva, presuntamente ineludible, "o galego ou é galego-portugués ou é galego-castelán”, mantra que se rexistra en moitos escritos seus da década de $1980^{17}$. O galego só ten futuro como variedade satelizada do portugués ou do castelán. Xa non considera posible que o proceso de elaboración realizado nos dous últimos séculos, onde foi fundamental o impulso dos escritores do Rexurdimento, como el mesmo recoñecera, converta o galego nunha lingua independente deses dous xigantes. O galego, para Carvalho un "anano", non tería a capacidade de desenvolver o seu rexistro culto nin de elaborar modelos lingüísticos para uso científico, administrativo ou literario, polo que tería que tomalos doutra lingua xa elaborada, dun dos dous "xigantes" que o rodean.

\section{ALICERCES PARA A REINTEGRACIÓN DO GALEGO}

A súa defensa de que o galego moderno é unha variedade do sistema lingüístico galego-portugués, onde se ten que reintegrar para frear a deriva castelanizadora, ten dous alicerces fundamentais (Fernán-Vello e Pillado 1986, pp. 176-178):

$1^{\mathrm{O}}$. A romanística universal, representada por un dos grandes mestres da lingüística moderna, Ramón Menéndez Pidal, que "indica de xeito absolutamente paladino nas primeiras páxinas da súa clásica Gramática histórica, tres romances actualmente na Península: un romance oriental, un romance central e un romance occidental, ao que Menéndez Pidal, como toda a romanística, chama galego-portugués".

2o. A tradición galeguista, e particularmente a figura de Castelao, que defendeu "unha aproximazón do galego ao portugués até confundirse ambas linguas.

17 "O galego ou é galego-portugués ou é galego-castelán. Ou somos unha forma do sistema occidental [galego-portugués] ou somos unha forma do sistema central [castelán]. Non hai outra alternativa. Un galego en oposición á vez ao portugués e ao castelán é imposíbel. Un enano non pode loitar con dous xigantes que cruzan os seus fogos" (Carballo 1979b, p. 149). 
Eu nunca cheguei a fazer unha manifestazón tan explícita”. En diversos textos apóiase, ademais de en Castelao, na autoridade de Murguía ${ }^{18}$.

Mestres da gramática histórica clasificaron o galego e o portugués nunha mesma unidade, pero na práctica prescindiron do galego. Meyer-Lübke (1926, pp. 51-53), a figura da romanística do período de entre séculos, no 1901 clasificou nove linguas: romanés, dalmático, rético, italiano, sardo, provenzal, francés, español e portugués; e considerou dialectos do portugués o galego, o portugués do norte, o portugués do sur, o azorés, o madeirés e o mirandés. Resulta claro que a súa formación sobre a realidade lingüística iberorrománica non era moi profunda nin de coñecemento directo, xa que consideraba o mirandés un dialecto portugués, cando se trata dunha variedade astur-leonesa, ou que ata o 1925 non lle ofreceu ó catalán o status de lingua diferente do provenzal. A súa auctoritas levou a outros romanistas a aceptaren esa clasificación e a consideraren o galego dialecto portugués.

No 1904 Menéndez Pidal (1968, pp. 1-2) seguiu a clasificación das linguas románicas de Meyer-Lübke, pero engadiu o catalán como 10 ํㅡㄹ lingua e cambiou o termo portugués por galego-portugués e rético por ladino ou reto-romano. En realidade, clasificou oito linguas e dous complexos lingüísticos: o galego-portugués co galego e portugués modernos; e o retorrománico, co romanche, friulano e ladino dolomítico.

Ata a década de 1970, durante case 150 anos de romanística científica, a presenza do galego nos manuais de referencia reducíase practicamente á mención da incuestionable fase medieval galego-portuguesa e a algunha outra mención para situalo como dialecto portugués por motivos xenéticos ou do español por motivos políticos. A romanística ignoraba o galego pola xeral ausencia de investigacións sobre ese "dialecto" portugués (Fernández Rei 1991, pp. 36-37; 1996, pp. 17-24; 2007, pp. 507-508).

O Lexikon der Romanistischen Linguistik (LRL), que se empezou a editar no 1988 e que se converteu no referente da romanística actual, consagrou a existencia do galego, do romanche, do friulano ou do corso. O volume VI, 2 (1994) ábrese con 8 entradas do galego, ás que seguen as 40 do portugués, separados claramente os dous idiomas ${ }^{19}$.

18 Son moitos os textos onde aparecen explicitados eses alicerces. En Carvalho (1983) poden verse, entre outros, no artigo do 1981 "O galego e Castelao" (pp. 112-113) e nos artigos do 1982 "De ortografía galega" (pp. 119-120) e "A incomodidade do galego" (pp. 124-126).

19 No LRL a lingua galega ten un tratamento tan digno como as linguas catalá e occitana (vol. V, 2, 1991), pero cunha diferenza salientable: ningunha entrada sobre o catalán se publicou neste idioma e ningunha do occitano na lingua de Oc, mentres que sete das entradas do galego están en galego e unha en alemán (Holtus 1994, pp. 1-129). 
Verbo do galeguismo histórico como alicerce da reintegración, na segunda metade do século XIX figuras relevantes como Antonio de la Iglesia ou Manuel Murguía defendían a identidade das linguas galega e portuguesa. Segundo Carme Hermida (1992, p. 111), no 1882 A. de la Iglesia incidía nesa identidade e afirmaba que, de traducirse ó galego unha poesía portuguesa, habería tan poucos cambios que pasarían desapercibidos. Murguía, piar do rexurdimento cultural e político de Galicia, no 1865 sostiña que o galego tivera "un completo desarrollo en el portugués" e que este "no es otra cosa que el gallego literario"; e no 1889, afirmaría que "el gallego es idioma nacional en Portugal".

A consideración de que eran o mesmo idioma contiña contradicións, pois nin A. de la Iglesia nin Murguía insinuaron ningún lusismo ortográfico: o primeiro mantivo unha postura etimoloxista verbo da grafía do fonema /S/, e aí remataba o seu achegamento á ortografía portuguesa. Murguía, nos poucos textos en galego que se lle coñecen, nin sequera adoptou este criterio. Outra contradición era a ausencia dunha identificación real entre as dúas linguas, pois non pretendían a submisión do galego ó portugués ${ }^{20}$.

Como sinalou González Seoane (1996, p. 123), esas invocacións son un recurso retórico co que reivindicar o valor e a dignidade da lingua, que responden "a un desexo de subliña-la importancia do galego como berce dunha moderna lingua de cultura". Por outra parte, Elias Torres, nun traballo sobre cultura portuguesa e lexitimación do sistema galeguista $(1999$, p. 273), tentaba "mostrar como nas bases do galeguismo ocupa desde os seus inícios um lugar preferente o reintegracionismo cultural (e a ameaça do político) como alicerce da legitimidade de existir e reforço da própria identidade e da soberania cultural". O reintegracionismo usado como un recurso retórico de lexitimación.

Fronte ó castelanismo de Sánchez Albornoz, Castelao manifestáballe a este nunha coñecida carta o desexo de que en Galicia se fale tan ben o galego coma o castelán e á vez desexaba "que el gallego se acerque y confunda con el portugués, de modo que tuviésemos así dos idiomas extensos y útiles" (Carvalho 1989, p. 91). Fronte a isto, en Sempre en Galiza (1944), proclamaba a independencia lingüística do galego ${ }^{21}$.

20 "Recoñecer que se trataba do mesmo idioma non significaba pedirlles ós galegos que escribisen en portugués nin aceptar que os textos medievais estivesen escritos nese idioma. A. de la Iglesia (1886), por exemplo, viuse na obriga de defende-la galeguidade dos documentos medievais e queixábase do comportamento daqueles que, en vendo un documento en galego, non dubidaban en afirmar que estaba escrito en portugués. Murguía (1896, pp. 178-179), aínda insistindo na identidade entre o galego e o portugués, lexitimou a pretensión dos galegos de escribiren no seu idioma e a creación dunha lingua literaria distinta do portugués" (Hermida 1992, pp. 112-113).

21 "Agás Menéndez y Pelayo non hai no centro de Hespaña un soio investigador que non se poña impúdicamente ao servizo do feito hexemónico e non trate de furtar ou amingoar os merecimentos lingoísticos 
Nunha análise da ideoloxía reintegracionista, Xavier Cordal Fustes (2009, pp. 352-353) salientaba que o proxecto lexitimador do reintegracionismo martela as citas de A. Villar Ponte e de Castelao, mais esquece o paradoxo de que case ninguén entre as elites do galeguismo deu o paso de escribir en portugués ${ }^{22}$.

Como recurso de lexitimación, para o galeguismo histórico o galego é pai do portugués (ou "lingua nai"), que foi lingua dun imperio colonial, lingua de varios países con prestixiosa literatura e indiscutida como unha lingua relevante, polo que o galego non é un patois; porén, que se use o portugués para defender o galego non ten efectos prácticos, porque non se está a defender o uso do portugués en Galicia.

\section{REMATE}

Levo 50 anos embarcado na tea de Penélope da nosa questione della lingua ${ }^{23}$, desde que na primavera de outono do 1971 comecei a asistir ás clases de lingua galega de don Ricardo, que tivera un papel decisivo na redacción da normativa da Academia (RAG 1971). No mesmo curso 1971-72, na materia de lingüistica xeral, fun alumno de Ramón Lorenzo, un dos autores do Gallego 1 (ILG 1971), pioneiro método de aprendizaxe do idioma en que o ILG discrepaba nalgúns puntos da normativa da Academia; e no curso seguinte, ademais de alumno de don Ricardo e de Lorenzo, funo de Constantino García, cando no ILG traballaban na redacción do volume 2 do método.

Na primavera do 1974 integreime no ILG no proxecto do Atlas lingüístico galego e desde aquela, ademais de recoller e estudar o galego oral, participei en traballos

e literarios de Galiza. O galego, para eles, foi o galaico-portugués; pero agora sóio existe o portugués porque o galego xa non é língoa... A política centralista manexou de tal maneira os vocablos "idioma" e "dialecto" - aplicando o primeiro somentes â língoa do Estado - que a xente iñorante chegou a creer que o galego proviña do castelán; pero cando esa iñorma xa non corría como válida, entón rebaixábase a categoría do galego decindo que era un dialecto do portugués. E semellante ideia, saída de Hespaña, sigue correndo antre estranxeiros de poucas letras. Ben saben os centralistas que a domiñación de Galiza endexamais será efeitiva antrementras fale un idioma diferente do castelán" (Castelao 1961, p. 287).

22 "Construíronse teorías sobre esa reticencia que van desde o menoscabo intelectual ata o paternalismo; chegouse a afirmar que aos líderes das Irmandades, e antes a Pondal ou a Curros, lles resultaba moi difícil a ortografía portuguesa. $\mathrm{O}$ desprezo das capacidades de quen foron sobranceiras figuras da Europa do seu tempo xa atacara o proxecto rosaliano, pero nas bibliotecas do precursor Sarmiento e tamén na de Rosalía, de Pondal, de Curros, de Risco ou de Otero - que lían grego e latín clásicos, francés, inglés, nalgún caso alemán e algunha outra fala exótica - o portugués era lingua preferente" (Cordal 2009, pp. 352-353).

23 Sobre os debates da questione della lingua galega e as propostas normativas desde 1950 á actualidade véxanse Alonso Pintos (2006), Fernández Rei (1991, 2001, 2008, 2018), Freixeiro Mato (2018), Herrero Valeiro (2011), Monteagudo (2003) e Sánchez Vidal (2010); sobre o reintegracionismo de Carvalho Calero e a codificación do galego véxanse Freixeiro Mato $(2011,2020)$ e Montero Santalha $(2011$, 2020a, 2020b). 
de codificación en que o Instituto andaba á procura da "olorosa pantera", da que se sente o recendo en todo o dominio lingüístico, pero non se dá cazado en ningures.

A comezos do século XIV, en De vulgari eloquentia, Dante Alighieri buscou o vulgar ilustre nas falas populares das rexións e das illas de Italia e tamén nas súas linguas literarias. Comparouno cunha pantera, que deixaba o seu perfumo en todos os bosques e prados, en todas as cidades de Italia, pero non se deixaba ver en ningures, porque en ningures tiña a súa gorida; con todo, podía sentirse máis nunha cidade ca noutra ${ }^{24}$.

A nosa "pantera", da que se sente o recendo nos soutos e nos lameiros, nos peiraos e nas vilas de Galicia (e das comarcas estremeiras e do Val do Ellas), ten tres esteos fundamentais: a fala viva, depurada de castelanismos; a tradición literaria medieval e contemporánea; e o portugués, sobre todo, para o arrequecemento do léxico culto. Parafraseando a Méndez Ferrín (1999, p. 149), esa lingua literaria, ese vulgar ilustre, ten que ser radical e puro, sen castelanismos, e asemade popular e útil para a comunicación da cultura moderna.

Desde a primeira edición da súa Gramática, don Ricardo andou á caza da "recendente pantera" nas fragas literarias das tres coroas poéticas do Rexurdimento (Rosalía, Curros e Pondal), sobre todo nas da cantora do Sar, e en menor medida, nos soutos e nos peiraos de Castelao, Manuel Antonio e Amado Carballo. Nos anos 80 tratou de cazala coa súa concepción, máis ou menos ambigua, do galego-portugués, cando se converteu no referente indiscutible do movemento reintegracionista de Galicia.

24 "XVI. Postquam venati saltus et pascua sumus Ytalie, nec pantheram quam sequimur adinvenimus, ut ipsam reperire possimus rationabilius investigemus de illa ut, solerti studio, redolentem ubique et necubi apparentem nostris penitus irretiamus tenticulis. [...] [4] Que quidem nobilissima sunt earum que Latinorum sunt actiones, hec nullius civitatis Ytalie propria sunt, et in omnibus comunia sunt: inter que nunc potest ilud disceni vulgare quod superius venabamur, quod in qualibet redolet civitate nec cubat in ulla. [5] Potest tamen magis in una quam in alia redolere [...] [6] Itaque, adepti quod querebamus, dicimus ilustre, cardinale, aulicum et curiale vulgare in Latio quod omnis latie civitatis est et nullius esse videtur, et que municipalia vulgaria omnia Latinorum mensurantur et ponderantur et comparantur" (Dante Alighieri 1995, pp. 104-106).

["XVI. Despois de bater os bosques e os prados sen ter atopado a pantera coa que empatizamos, debemos seguir os seus pasos con métodos máis racionais, se queremos perseguila, e ser o suficientemente intelixentes como para que caia nas redes ben atadas do noso enxeño esta fera da que notamos o recendo en todas as partes, pero que non vemos en ningures. [...] [4] E certamente os signos máis nobres das accións dos italianos non son en absoluto o patrimonio exclusivo de ningunha cidade de Italia, senón comúns a todos. Ben, entre estas podemos recoñecer ese vulgar que estivemos perseguindo e que se deixa cheirar en todas as cidades pero que non fai a gorida en ningunha. [5] Non obstante, podemos sentir este recendo máis nunha cidade que noutra [...] [6] Xa atopamos o que buscabamos. Dicimos, entón, que o vulgar ilustre, cardinal, áulico e curial de Italia é o de todas as cidades, sen ser patrimonio exclusivo de ningunha; é aquel, en definitiva, a partir do cal podemos medir, sopesar e comparar todos os vulgares municipais dos italianos"]. 
É innegable que estamos perante unha figura da nación que, como el mesmo lle dixo a Carmen Blanco (1989, p. 226), "toda a miña vida estivo consagrada ao meu xeito, por suposto, non ao xeito dos demais, a traballar, non pola Galiza autonómica, que é un conceito dunha limitación circunstancial moi concreta, senón pola grande Galiza utópica, se se quer, que constituía o ideal dos homes que foron os meus mestres".

Saúde e Patria da Lingua

\section{REFERENCIAS BIBLIOGRÁFICAS}

Alonso Pintos, Serafín (2000). O ideal de lingua na Gramática de Carballo Calero. Grial, 147, 461-474.

Alonso Pintos, Serafín (2006). O proceso de codificación do galego moderno (19501980). [A Coruña]: Fundación Pedro Barrié de la Maza.

Álvarez, Rosario (2011). A gramática galega no século XX. O contributo de Carvalho Calero. En: Carlos C. Biscainho Fernandes e Xosé M. Sánchez Rei, eds. Ricardo Carvalho Calero: ciencia, literatura e nación. A Coruña: Universidade da Coruña, 13-29. https://doi.org/10.17979/spucdc.9788497497718.013

Blanco, Carmen (1989). Conversas con Carballo Calero. Vigo: Galaxia.

Carballo Calero, Ricardo (1966). Gramática elemental del gallego común. Vigo: Galaxia.

Carballo Calero, Ricardo (1968). Gramática elemental del gallego común. 2ae ed. Vigo: Galaxia.

Carballo Calero, Ricardo (1969). Sobre os dialectos do galego. Grial, 23, 1-15.

Carballo Calero, Ricardo (1970). Gramática elemental del gallego común. $3^{a}$ ed. Vigo: Galaxia.

Carballo Calero, Ricardo (1974). Gramática elemental del gallego común. 4⿳亠丷a ed. Vigo: Galaxia.

Carballo Calero, Ricardo (1975). Ortografía galega. La Voz de Galicia 27/VII/1975. Carballo Calero, Ricardo (1979a). Gramática elemental del gallego común. 7ª ed. Vigo: Galaxia.

Carballo Calero, Ricardo (1979b). Sobre a nosa lingua. Grial, 64, 140-152.

Carballo Calero, Ricardo (2006). Epistolario a Francisco Fernández del Riego. Vigo: Galaxia. Transcrición e edición de Dolores Vilavedra e Montserrat Pena.

Carvalho Calero, Ricardo (1983). Da fala e da escrita. Ourense: Galiza Editora. Carvalho Calero, Ricardo (1989). Escritos sobre Castelao. Barcelona: Sotelo Blanco. 
Castelao, A. Daniel (1961). Sempre en Galiza. 2ª ed. Buenos Aires: Centro Ourensano [1ํㅡ ed.: 1944].

Cordal Fustes, Xabier (2009). A ideoloxía reintegracionista. A Trabe de Ouro, 79, 347-367.

Dante Alighieri (1995). De vulgari eloquentia. Vic: Eumo Editorial. Edició bilingüe. Fernández Rei, Francisco (1991). A 'questione della lingua' galega. A Trabe de Ouro, 5, 29-40. [Reproducido en: Henrique Monteagudo, ed. Estudios de sociolingüistica galega. Sobre a norma do galego culto. Vigo: Galaxia, 1995, 177-195].

Fernández Rei, Francisco (1996). A posición do galego, lingua románica reemerxente. En: Ramón Lorenzo e Rosario Álvarez, coords. Homenaxe á Profesora Pilar Vázquez Cuesta. Santiago de Compostela: Universidade de Santiago de Compostela, 15-46.

Fernández Rei, Francisco (2001). A Proposta de acordo normativo do 2001. Notas e documentos sobre a questione della lingua galega. A Trabe de Ouro, 48, 529-552.

Fernández Rei, Francisco (2007). A problemática elaboración do galego moderno. A Trabe de Ouro, 72, 503-526.

Fernández Rei, Francisco (2008). A creación do Instituto da Lingua Galega en 1971 e o desencontro normativo coa Academia. En: Xosé L. Axeitos, Emilio Grandío Seoane e Ramón Villares, eds. A patria enteira. Estudos en homenaxe a Xosé Ramón Barreiro. Santiago de Compostela: Real Academia Galega / Universidade de Santiago de Compostela / Consello da Cultura Galega, 985-1009.

Fernández Rei, Francisco (2018). A codificación do galego moderno. O papel do Instituto da Lingua Galega e da Real Academia Galega nese proceso. En: Javier Giralt Latorre e Franco Nagore Laín, eds. Lenguas minoritarias de Europa y estandarización. Zaragoza: Prensas de la Universidad de Zaragoza, 77-112.

Fernán-Vello, Miguel A. e Pillado Mayor, Francisco (1986). Conversas en Compostela con Carballo Calero. Barcelona: Sotelo Blanco.

Freixanes, Víctor F. (2020). Ricardo Carballo Calero na Academia. En: Anxo Tarrío e Armando Requeixo, coord. Estudos arredor de Ricardo Carvalho Calero. Cadernos Ramón Piñeiro XL. Santiago de Compostela: Centro Ramón Piñeiro para a Investigación en Humanidades, 103-116.

Freixeiro Mato, Xosé R. (2011). Carvalho Calero e a lingua galega: coherencia, compromiso e visión de futuro. En: Carlos C. Biscainho Fernandes e Xosé M. Sánchez Rei, eds. Ricardo Carvalho Calero.: ciencia, literatura e nación. A Coruña: Universidade da Coruña, 67-85. 
Freixeiro Mato, Xosé R. (2018). As primeiras normas da Academia e a perda da súa auctoritas na codificación do galego. Verba, 45, 299-340. http://dx.doi. org/10.15304/verba.45.4207

Freixeiro Mato, Xosé R. (2020). Carvalho Calero e a codificación da lingua galega. Sermos Galiza, 397, 38-42.

González González, Manuel (2020). A Gramática elemental del gallego común e a creación da cátedra de galego na USC, dúas referencias na historia do galego do século XX. En: Anxo Tarrío e Armando Requeixo, coords. Estudos arredor de Ricardo Carvalho Calero. Cadernos Ramón Piñeiro XL. Santiago de Compostela: Centro Ramón Piñeiro para a Investigación en Humanidades, 117-135.

González Seoane, Ernesto X. (1996). O debate sobre a independencia do galego na última década do século XIX. En: Ramón Lorenzo e Rosario Álvarez, coords. Homenaxe á profesora Pilar Vázquez Cuesta. Santiago de Compostela: Universidade de Santiago de Compostela, 121-131.

Hermida, Carme (1992). Os precursores da normalización. Defensa e reivindicación da lingua galega no Rexurdimento (1840-1891). Vigo: Edicións Xerais de Galicia.

Herrero Valeiro, Mário J. (2011). Guerra de grafias e conflito de elites na Galiza contemporânea (textos e contextos até 2000). [A Coruña]: Através editora.

Holtus, Günter, Metzeltin, Michel e Schmitt, Christian, eds. (1994). Lexikon der Romanistischen Linguistik (LRL). VI (2). Galegisch, Portugiesisch. Gallego, Português. Tübingen: Niemeyer.

ILG $=$ Instituto de la Lengua Gallega (1971). Gallego 1. Santiago de Compostela: Universidad de Santiago de Compostela.

Lapa, Manuel Rodrigues (1973). A recuperação literária do galego. Grial, 41, 278 287.

Mariño Paz, Ramón (2002). A obra lingüística de Carvalho Calero. En: Teresa López e Francisco Salinas, eds. Actas do Simposio Ricardo Carvalho Calero. "Memoria do século". A Coruña: Universidade da Coruña / Asociación Socio-Pedagóxica Galega, 67-106.

Méndez Ferrín, Xosé L. (1999). Alonso e a saudade. En: Rosario Álvarez e Dolores Vilavedra, coords. Cinguidos por unha arela común. Homenaxe ó profesor Xesús Alonso Montero. Santiago de Compostela: Universidade de Santiago de Compostela, I, 147-151.

Menéndez Pidal, Ramón (1968). Manual de gramática histórica española. Madrid: Espasa-Calpe. [1 ${ }^{a}$ ed.: 1904].

Meyer-Lübke, Wilhelm (1926). Introducción a la lingüística románica. Madrid: Centro de Estudios Históricos. [1ª ed.: 1901. Versión de la tercera edición alemana, con notas y adiciones por Américo Castro]. 
Monteagudo, Henrique (2003). A demanda da norma. Avances, problemas e perspectivas no proceso de estandarización do idioma galego. En: Henrique Monteagudo e Xan M. Bouzada, eds. O proceso de normalización do idioma galego 1980-2000. Vol. III. Elaboración e difusión da lingua. Santiago de Compostela: Consello da Cultura Galega, 37-129.

Monteagudo, Henrique (2020). A individualidade do galego no pensamento lingüístico de Ricardo Carballo Calero. En: Francisco Cidrás, ed. Ricardo Carvalho Calero, as formas do compromiso: Día das Letras Galegas 2020. Santiago de Compostela: Universidade de Santiago de Compostela, 329-357.

Montero Santalha, J. Martinho (2011). Etapas no pensamento lingüístico de Ricardo Carvalho Calero. En: Carlos C. Biscainho Fernandes e Xosé M. Sánchez Rei, eds. Ricardo Carvalho Calero: ciencia, literatura e nación. A Coruña: Universidade da Coruña, 127-145. https://doi.org/10.17979/ spucdc. 9788497497718.127.

Montero Santalha, J. Martinho (2020a). De Carballo a Carvalho. En: Bernardo Máiz, coord. RCC. O Carballo que fun en Ferrol. Aproximación a Ricardo Carvalho Calero. Ferrol: Club de Prensa, 107-124.

Montero Santalha, J. Martinho (2020b). O contributo lingüístico de Carvalho Calero. En: F. Cidrás, ed. Ricardo Carvalho Calero, as formas do compromiso. Día das Letras Galegas 2020. Santiago de Compostela: Universidade de Santiago de Compostela, 283-304.

RAG = Real Academia Galega (1971). Normas ortográficas e morfolóxicas do idioma. A Cruña: Real Academia Galega.

Sánchez Vidal, Pablo (2010). O debate normativo da lingua galega (1980-2000). [A Coruña]: Fundación Barrié de la Maza.

Santamarina, Antón (1989). Estado e tarefas da lingüística galega. En: Dieter Kremer, ed. Actes du XVIII ${ }^{e}$ Congrès International de Linguistique et de Philologie Romanes (Université de Trier, 1986). Tübingen: Niemeyer 7, 289-310.

Torres Feijoo, Elías (1999). Cultura portuguesa e legitimação do sistema galeguista: historiadores e filólogos (1880-1891). Ler História, 36, 273-318.

USC $=$ Universidade de Santiago de Compostela (1977). Bases prá unificación das normas lingüísticas do galego. Resume dos seminarios celebrados na Universidade de Santiago de Compostela desde decembro de 1976 a xuño de 1977. Madrid: Anaya. 